\title{
Corrigendum to "Pulsed Electromagnetic Fields Improve Tenogenic Commitment of Umbilical Cord-Derived Mesenchymal Stem Cells: A Potential Strategy for Tendon Repair-An In Vitro Study"
}

\author{
Antonio Marmotti $\left(\mathbb{D},{ }^{1,2}\right.$ Giuseppe Maria Peretti $\left(\mathbb{D},{ }^{3,4}\right.$ Silvia Mattia, ${ }^{2}$ Laura Mangiavini $\left(\mathbb{D},{ }^{3}\right.$ \\ Laura de Girolamo (D), ${ }^{3}$ Marco Viganò, ${ }^{3}$ Stefania Setti $\left(\mathbb{D},{ }^{5}\right.$ Davide Edoardo Bonasia, ${ }^{1}$ \\ Davide Blonna $\mathbb{D}^{1},{ }^{1}$ Enrico Bellato $\mathbb{D}^{1},{ }^{1}$ Giovanni Ferrero, ${ }^{1}$ and Filippo Castoldi ${ }^{1}$ \\ ${ }^{1}$ Department of Orthopaedics and Traumatology, University of Turin, Torino, Italy \\ ${ }^{2}$ Molecular Biotechnology Center, University of Turin, Torino, Italy \\ ${ }^{3}$ IRCCS Istituto Ortopedico Galeazzi, Milano, Italy \\ ${ }^{4}$ Department of Biomedical Sciences for Health, University of Milan, Milano, Italy \\ ${ }^{5}$ IGEA SpA Clinical Biophysics, Carpi, Modena, Italy
}

Correspondence should be addressed to Antonio Marmotti; antonio.marmotti@inwind.it

Received 20 March 2019; Accepted 25 March 2019; Published 2 May 2019

Copyright (c) 2019 Antonio Marmotti et al. This is an open access article distributed under the Creative Commons Attribution License, which permits unrestricted use, distribution, and reproduction in any medium, provided the original work is properly cited.

In the article titled "Pulsed Electromagnetic Fields Improve Tenogenic Commitment of Umbilical Cord-Derived Mesenchymal Stem Cells: A Potential Strategy for Tendon Repair-An In Vitro Study" [1], there was an error in the affiliation details of Drs. Laura Mangiavini, Laura de Girolamo, and Marco Viganò, as they were wrongly affiliated to "Department of Biomedical Sciences for Health, University of Milan, Milano, Italy." However, they should be affiliated to "3IRCCS Istituto Ortopedico Galeazzi, Milano, Italy." The corrected authors' list and affiliations are shown above.

\section{References}

[1] A. Marmotti, G. M. Peretti, S. Mattia et al., "Pulsed electromagnetic fields improve tenogenic commitment of umbilical cordderived mesenchymal stem cells: a potential strategy for tendon repair-an in vitro study," Stem Cells International, vol. 2018, Article ID 9048237, 18 pages, 2018. 


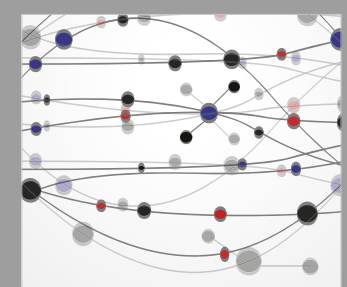

The Scientific World Journal
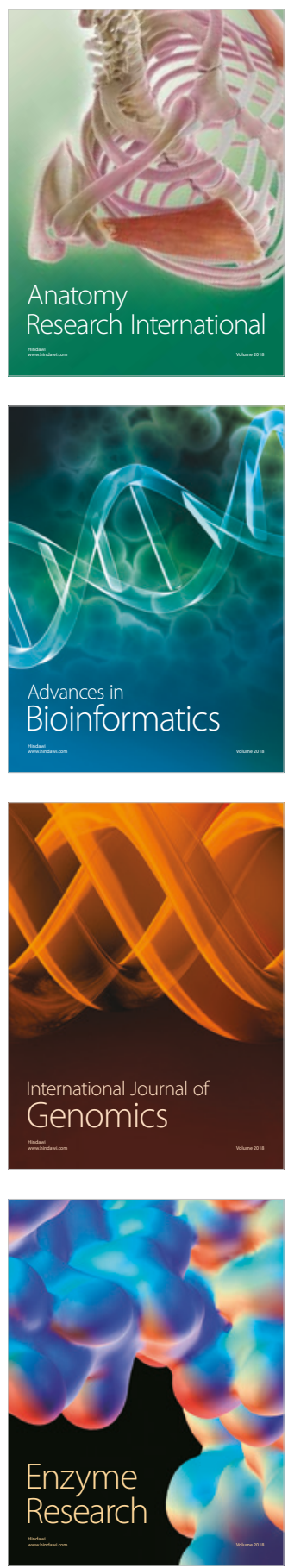
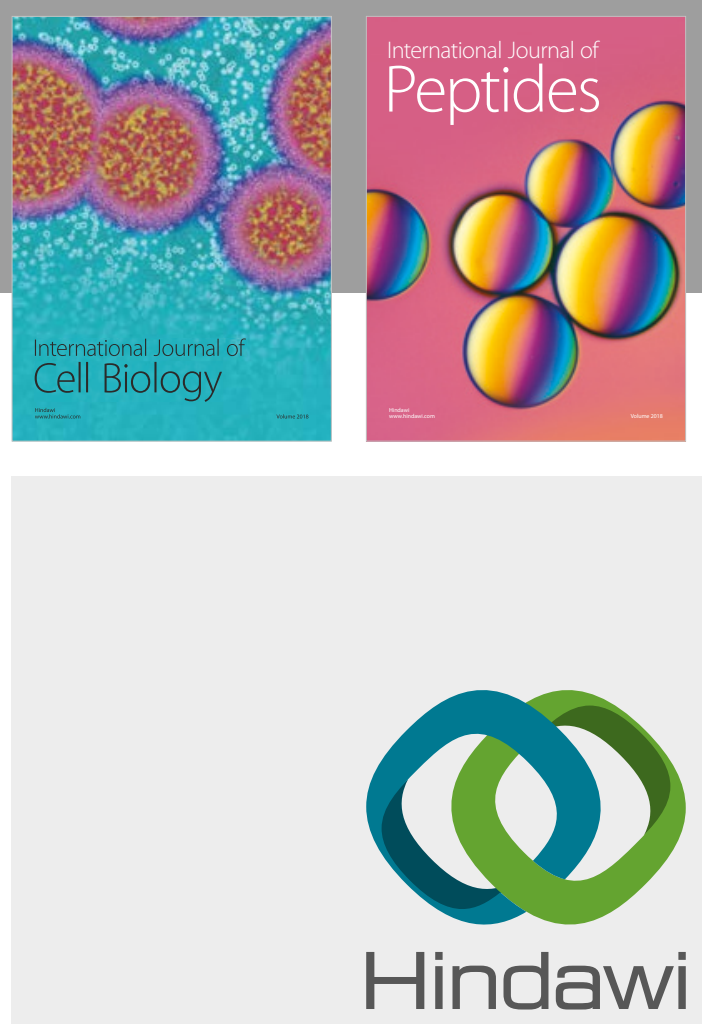

Submit your manuscripts at

www.hindawi.com
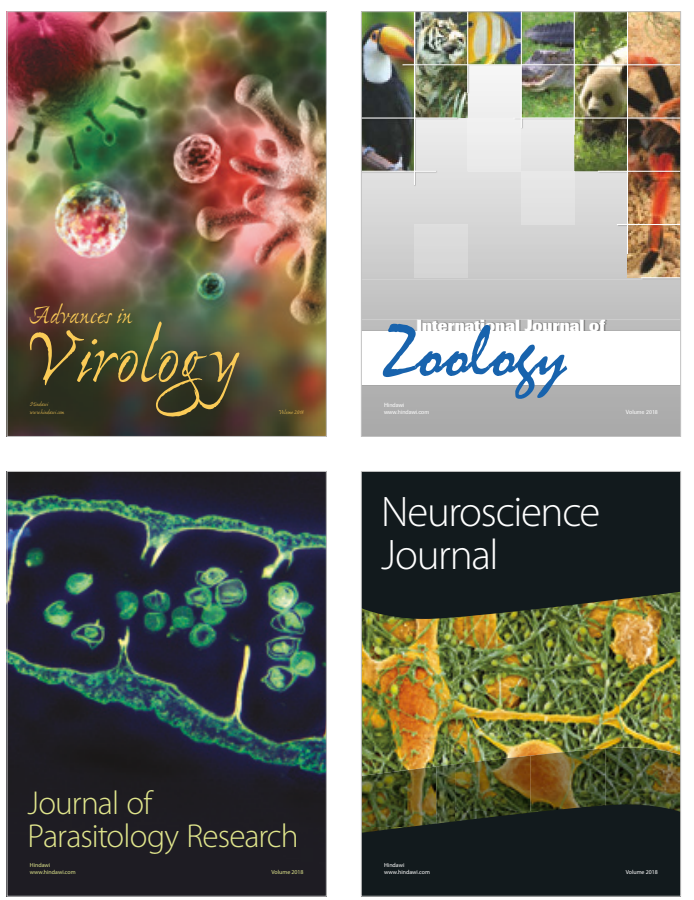
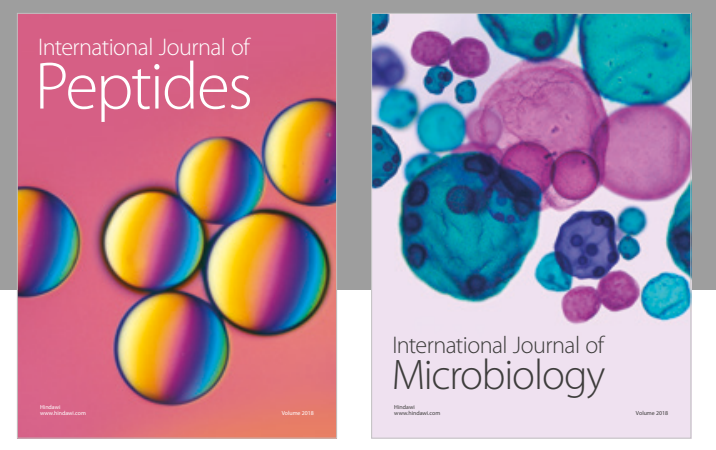

nternational Journal of Microbiology
Journal of
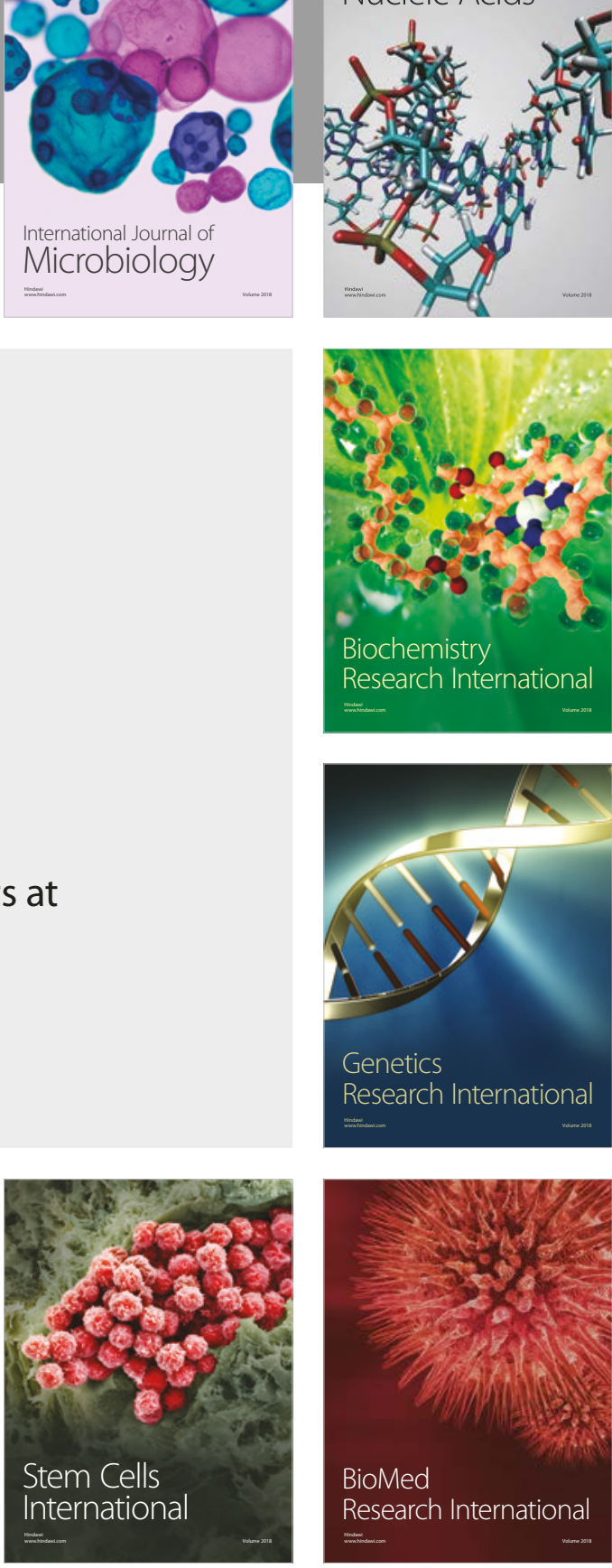
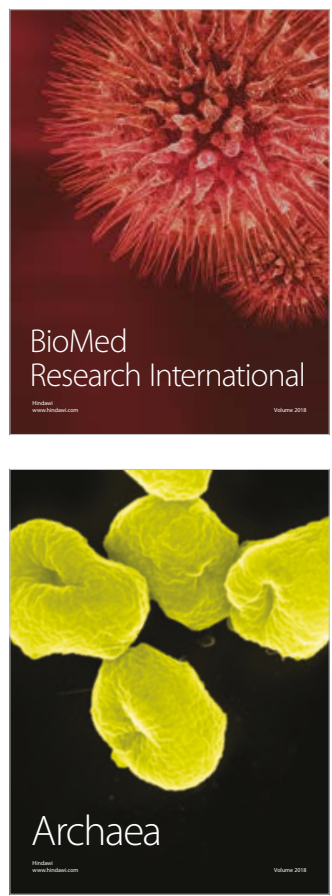